\title{
Problem Based Learning como metodologia inovadora no ensino de graduação em saúde
}

Ubirajara José Picanço de Miranda Junior*

A o ser convidado pela Dra. Paula Broeiro, diretora da Revista Portuguesa de Medicina Geral e Familiar (RPMGF), para falar sobre Aprendizagem Baseada em Problemas (ABP), ou Problem Based Learning (PBL), me considerei honrado e com grande prazer de ter a oportunidade de promover este intercâmbio de caráter internacional e de estreitamento de relações entre países de língua portuguesa, no âmbito académico de ensino e pesquisa em saúde.

Para discorrer sobre o tema, faz-se necessário apontar algumas peculiaridades sobre a constante evolução da ciência e sua consequente especialização, que acabou por criar uma visão restrita e fragmentada do conhecimento, ${ }^{1}$ que tem se refletido no processo educacional, impondo uma organização curricular em disciplinas e conteúdos. ${ }^{2}$

Há um reconhecimento internacional sobre a necessidade de mudança na formação de profissionais da área de saúde face à inadequação do aparelho formador em responder às demandas sociais. As instituições têm sido estimuladas a transformarem-se na direção de um ensino que valorize uma profissionalização que priorize o humanismo, a equidade e a qualidade da assistência. ${ }^{3}$

Assim, seguindo no sentido contrário do ensino tradicional, onde se apresentam os conteúdos em forma de roteiros pré-determinados, o PBL surge como uma quebra de paradigma no ensino, levando os alunos a identificarem as suas reais necessidades de aprendizagem. ${ }^{4}$

Trata-se de uma metodologia de ensino e aprendizado utilizada na área da saúde, que foi implantada ini-

*Docente do curso de Medicina. Escola Superior de Ciências da Saúde (ESCS). Médico da Secretaria de Estado de Saúde do Distrito Federal (SES/DF), Brasil. cialmente na Universidade de McMaster no Canadá e em Maastricht na Holanda, na década de 1960, como proposta pedagógica que consiste no ensino centrado no estudante e baseado na solução de problemas, reais ou simulados. ${ }^{5}$

No Brasil, esta metodologia vem sendo utilizada desde o final da década de 90, expandindo-se, desde então, para diversas instituições de ensino superior da área da saúde.

O Ministério da Educação, em consonância com o Ministério da Saúde, vem investindo no estabelecimento de mudanças no ensino da saúde, propondo novas diretrizes curriculares nacionais utilizando metodologias inovadoras de caráter problematizador. Os projetos pedagógicos para tal finalidade preveem a construção coletiva, centrada no aluno como sujeito da aprendizagem e apoiada no professor como facilitador e mediador do processo ensino-aprendizagem. ${ }^{6}$

Para o curso de graduação em medicina é estabelecido, como objetivo do perfil desse egresso, ser um "profissional médico, com formação generalista, humanista, crítica e reflexiva". ${ }^{7}$

Em Brasília, a Escola Superior de Ciências da Saúde (ESCS), instituição pública distrital de ensino superior em saúde, desde a sua criação em 2001, adota metodologias problematizadoras como base do seu projeto político pedagógico, contando com dois cursos: medicina e enfermagem.

A ESCS se diferencia por promover um programa educacional de integração ensino-serviço com a comunidade desde o início dos dois cursos de graduação, onde o aluno vivencia as atividades em unidades de atenção básica da saúde, especialmente do Programa de Saúde da Família nos primeiros anos de formação, seguido nos anos finais de envolvimento com os níveis de maior complexidade do sistema de saúde. 
Os principais pontos de interesse do PBL são:

- O estudante e o grupo tutorial serem a base ou o elemento central do método. Aos alunos, reunidos em pequenos grupos, são apresentados um problema fictício ou real pré-elaborado, acompanhado por um tutor docente, sendo estimulados a discutir e elaborar hipóteses e propostas de solução;

- O currículo é integrado e integrador, com uma linha condutora geral, no intuito de facilitar e estimular o aprendizado;

- A escola oferece grande variedade de oportunidades de aprendizado por meio de laboratórios, ambulatórios, experiências e estágios hospitalares e comunitários, bibliotecas tradicionais e acesso a meios eletrónicos (Internet);

- O aluno é precocemente inserido em atividades de saúde, facto fundamental para a sua vida profissional;

- O conteúdo curricular contempla os problemas mais frequentes e relevantes a serem enfrentados na vida de um profissional de saúde;

- O aluno é constantemente avaliado em relação ao seu conhecimento cognitivo e ao desenvolvimento de habilidades e atividades necessárias à profissão;

- O currículo é flexível e pode ser modificado;

- O trabalho em grupo e a cooperação interdisciplinar e multiprofissional são estimulados.

O PBL estimula, portanto, o protagonismo do aluno neste processo, valorizando a forma como ocorre o aprendizado, além do conteúdo a ser aprendido, permitindo que ele aprenda como aprender, bem como o desenvolvimento de habilidades técnicas, cognitivas, de comunicação e atitudinais, promovendo assim o gerenciamento do aprendizado pelo próprio estudante. ${ }^{8}$

Não se pode deixar de considerar algumas fragilidades do uso do PBL, destacando-se:

- Dificuldade em se institucionalizar uma inovação, com uma nova abordagem metodológica;

- A quebra da passividade dos estudantes na aquisição do conhecimento gera desconforto e requer uma postura proativa, o que nem sempre é bem assimilado e aceite por todos os estudantes;

- Além disso, a falta de experiência de professores com os fundamentos teóricos e práticos do PBL é outro fator limitante. ${ }^{5}$

A implementação do PBL requer maior investimento em recursos materiais, para que sejam disponibili- zados aos estudantes os mais variados recursos educacionais, além da ampliação do corpo docente. É imprescindível também que haja o desenvolvimento de um programa de capacitação permanente de professores e alunos, para que estes se identifiquem e familiarizem com o novo modelo pedagógico. ${ }^{4}$

Finalmente, deve ser ressaltado que as vantagens e limitações do PBL devem ser analisadas, considerandose ainda as condições específicas de cada currículo. Pode-se concluir que a metodologia do PBLé uma abordagem educacional que parece trazer respostas consideradas centrais no processo de reforma do ensino superior, pois permite refletir o processo de ensino das instituições de ensino superior, especialmente no setor saúde, rompendo definitivamente com o modelo tradicional, centralizador, buscando uma integração mais completa, efetiva e eficaz da teoria com a prática em seus aspetos biopsicossociais.

\section{REFERÊNCIAS BIBLIOGRÁFICAS}

1. Pombo O. Interdisciplinaridade e integração dos saberes. Liinc em Revista. 2005;1(1):3-15.

2. Gerhard AC, Rocha Filho JB. A fragmentação dos saberes na educação científica escolar na percepção de professores de uma escola de ensino médio [The knowledge fragmentation of scientific school education on the view of high school teachers]. Investigações em Ensino de Ciências. 2012;17(1):125-45. Portuguese

3. Cyrino EG, Toralles-Pereira ML. Estratégias de ensino-aprendizado por descoberta na área da saúde [Discovery-based teaching and learning strategies in health: problematization and problem-based learning]. Cad Saúde Pública. 2004;20(3):780-8. Portuguese

4. Wood DF. Problem based learning. BMJ. 2003;326(7384):328-30.

5. Borges MC, Chachá SG, Quintana SM, Freitas LC, Rodrigues ML. Aprendizado baseado em problemas [Problem-based learning]. Medicina (Ribeirão Preto). 2014;47(3):301-7. Portuguese

6. Conselho Nacional de Educação. Parecer CNE/CES n $1.133 / 2001$, de 7 de agosto de 2001: diretrizes curriculares nacionais dos cursos de graduação em enfermagem, medicina e nutrição. Brasília: Ministério da Educação; 2001.

7. Conselho Nacional de Educação. Parecer CNE/CES n 116/2014, de 20 de junho de 2014: diretrizes curriculares nacionais do curso de graduação em medicina. Brasília: Ministério da Educação; 2014.

8. Secretaria de Estado de Saúde do Distrito Federal - FEPECS/ESCS. Plano de desenvolvimento institucional - PDI (2012-2016). Brasília: Secretaria de Estado de Educação; 2012.

CONFLITO DE INTERESSES

O autor declara não ter conflitos de interesses.

ENDEREÇO PARA CORRESPONDÊNCIA

up.picanco@globo.com 